\title{
Exploring gender disparities in science and mathematics classrooms in the basic education
}

\author{
Morales, Marie Paz E. \\ Educational Policy Research and Development Center, Philippine Normal University, Philippines \\ (morales.mpe@pnu.edu.ph)
}

Avilla, Ruel A.

Faculty of Science, Technology and Mathematics, Philippine Normal University, Philippines (avilla.ra@pnu.edu.ph)

Espinosa, Allen A.

Faculty of Science, Technology and Mathematics, Philippine Normal University, Philippines (espinosa.ae@pnu.edu.ph)

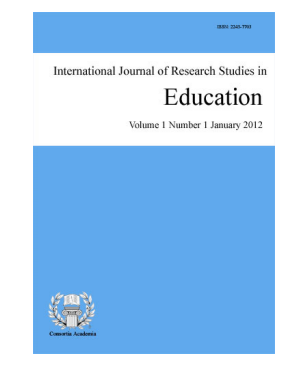

ISSN: 2243-7703 Online ISSN: 2243-7711

OPEN ACCESS

\begin{abstract}
The present study assessed gender equality in science and mathematics classrooms in terms of instructional language, classroom materials, teaching aids, textbooks, curriculum, activities, and interactions as well as classroom management. Mixed methods research was 7 employed in the study. Quantitative data were gathered using the Observation Protocol for Gender Equity in Classroom (Espinosa \& Morales, 2015). Interviews, focus group discussions and classroom observations generated the qualitative data in the study. Participants in the study were conveniently selected by the researchers. Analysis of the interview transcripts showed agreement and disagreement with the observation reports. However, in most instances, participants believed that equality in gender should always prevail in the classroom and that if disparity manifests, both the student and the teacher are responsible in maintaining equality in the classroom.
\end{abstract}

Keywords: gender disparity; gender equality; science education; mathematics education 


\section{Exploring gender disparities in science and mathematics classrooms in the basic education}

\section{Introduction}

After UNESCO's overarching goal of achieving Education for ALL (EFA) by the year 2015, what would be the next step for education? A country with literate citizenry may not be enough to match the growing global developments. Concerns and ideologies are now shifting from education for the nation to education for globalization. Al-Rodhan and Stoudmann (2006) define globalization as the process of international integration arising from the interchange of world views, products, ideas and other aspects of culture. With a trend towards globalization, UNESCO further visualizes education to provide globally competitive citizenry. Education is a right, as called for by UNESCO (2014) that transforms lives when it is accessible to all, relevant and underpinned by core shared values. Quality education is the most influential force for alleviating poverty, improving health, and livelihoods, increasing prosperity and shaping more inclusive, sustainable and peaceful societies, it is in everyone's interest that it is at the center of the post - 2015 development agenda.

As stressed, UNESCO's post 2015 agenda (UNESCO, 2014) claim education as a fundamental human right and a public good which is key to ending poverty and building an equitable and sustainable future. It is believed to hold a unique role within the new development agenda: it has the power to underpin transformative change, it can provide opportunity; and it can protect the lives of hundreds of millions of people worldwide. As asserted by the post 2015 agenda, transformative education must be at the heart of the post-2015 agenda if a sustainable and equitable future is to be realized. Transformative education is equitable education which must include concrete steps to overcome all forms of discrimination, including those based on disability, gender, race, ethnicity, religion, language, sexual orientation and/or socio-economic status. Taken as a fundamental right, equitable inclusive quality education and lifelong learning for all are the major goals of post - 2015 agenda.

As targeted by 2030, all children must complete full cycle of inclusive quality and gender sensitive education with relevant learning achievements determined through different measures. UNESCO, thus, recommends to its member states: "Ensure equitable quality education and lifelong learning for ALL by 2030" as a possible overarching education goal, aiming to achieve - just, inclusive, peaceful and sustainable societies. This overarching goal is translated into specific global targets to which countries would commit and could be held accountable, and for which corresponding indicators will be developed. Specific priority areas identified are basic education; post-basic \& tertiary education; youth \& adult literacy; skills for work \& life; quality and relevant teaching \& learning; and financing education. As proposed, UNESCO holds that gender equality requires continued and central attention in post-2015 education agenda.

Revisiting one of the six Education for All goals - to eliminate gender biases in the basic education by 2005 and gender equality in education can be reached by 2015 - EFA wants women to have full and equal opportunities in quality basic education. This has been tracked as the Millennium Development Goal of East Asia and Pacific Regional UN Girls' Education Initiative (UNGEI, 2010). The aim is to ensure the availability of quality education for all girls and boys across East Asia and the Pacific region. Achieving gender parity or equal proportions of girls and boys in both the primary and the secondary levels, was the first attempt to achieve this goal. To note, Philippines was one of the countries identified which indicated near parity in 2005. In fact, in 2008, Manahan (2010) quoted Pres. Gloria Macapagal-Arroyo of saying, "We are proud of the gains in gender equality in the Philippines. We are number one in the world in terms of gender parity in literacy and in health." Additionally, the country has been identified to score relatively high on global gender equality indices indicating an overall improvement in recent decades in the situation of women (Social Watch, 2007).

Several researches (Balisacan \& Piza, 2003; Balisacan \& Fuwa, 2004; Cruz, 2007; Manahan, 2010) found 
the same theme on gender parity in the Philippines. However, as reported by Mesa (2007), the gender parity status of the country has already been stagnant and is believed that as a country, we will not be able to reach the 2015 goal of gender equality. Additionally, Mesa (2007) stressed that country studies dominate the research arena on gender disparities and if we want to elevate our country status to match the global target, there is need to assess gender disparity within the country.

Even with a good bearing in gender parity which is indicated by an overall improvement, the Philippines is still far from achieving gender equality in education (UNGEI, 2010). As defined, gender equality in education also includes equality in the quality of education received and in the teaching and learning processes (gender equality in education) as well as in the opportunities available through education (gender equality through education). Apparently, in classrooms, gender biases can be observed in textbooks and learning materials, with women and men often portrayed in stereotypical roles (e.g., girls looking after younger siblings, women doing errands, boys playing football, men as policemen, doctors or leaders, etc.). It is also observed in the practices of teachers and how they interact with students - girls/women and boys/men still often given tasks which are considered typically 'feminine' or 'masculine' academic and training fields (UNGEI, 2010). Thus, UNESCO (2007) recommends that while gender parity indices are computed and utilized to monitor progress, combined quantitative and qualitative aspects of achieving gender equality should also be looked into.

Indicators, data, and information are needed to assess the extent to which gender equality is being achieved in terms of processes and outcomes in education. This will then point to understanding gender gaps that will lead to actions addressing such gaps which will eventually bring our gender equality status to the targeted gender equality in quality education geared at reaching EFA goals and peeping at post -2015 agenda. Thus, the objective of the present study is to determine gender gaps in Science and Math Education quality offered in the basic education. Specifically, the study aims to assess the gender equality in education quality in the aspects of instructional language, classroom materials and teaching aids, textbooks, curriculum, activities and interactions, and classroom management.

\section{Literature and Background}

\subsection{Terminologies on Gender Studies}

Generally, gender studies define gender equality as the principle of assessing quality of men and women and their right to enjoy equal conditions realizing their full human potentials to contribute to and benefit from the results of development, and with the state recognizing that all human beings are free and equal in dignity and rights. Gender equity is described as how fair and just the distribution of benefits and responsibilities between men and women. It recognizes that men and women have unique needs and power that these should be identified and addressed in a manner that rectifies the imbalance between them. Gender sensitivity connotes the ability to understand and consider the socio-cultural factors underlying gender-based discrimination, socialization of men and women into certain behaviors or opportunities, power relations between men and women, as well as the different needs, problems and levels of access to resources that they have. Lastly, gender discrimination refers to any distribution, exclusion or restrictions made on the basis of socially constructed gender roles and norms that prevent a person, female or male, from enjoying full human rights.

\subsection{Gender and Education}

In a report made by UNESCO in 2007, it is emphasized that by year 2015 all children especially girls, those coming from difficult situation and ethnic groups are given free and complete good quality primary education and that gender equality in education is also achieved in which women will have full and equal opportunities in quality basic education. UNESCO's (2007) Millennium Development Goal (MDG) to promote gender equality and empower women was launched in May 2002 by UNGEI aimed to eliminate gender biases in the basic education by 2005 and at all levels by the year 2015. This MDG program pursued to establish networks and 
partnerships among experts and organization promoting equality in education. One major goal of East Asia and Pacific Regional UNGEI was to ensure availability of quality education for all girls and boys across region. As a monitoring scheme, UNESCO (2007) used Gender Parity indices to indicate equal or near-equal proportions for girls and boys in the different levels of education. Accordingly, of the 19 countries with available data for 2005, only 16 reached the targeted gender parity in primary education while only 9 countries reached gender parity at the secondary level in 2005. Philippines was included in the list of 16 countries that reached gender parity in primary education but not in secondary and tertiary levels.

In the past trends, 1991-2005, as shown by EFA's Global Monitoring Report (GMR, 2008), Philippines was included among the list of countries which are at risk of not being able to achieve gender parity in all levels by 2015 or 2025. Social Watch (2007) supported this report and acknowledged that although the Philippines remains among the countries with a relatively high gender equity index, scoring alongside Australia and Latvia, its pace of development in gender equity over the past years is dismal prodding Social Watch International monitors to rate Philippines' GEI progress as stagnant. Accordingly, its pace of development is almost at the same rate as countries with the lowest scores in the GEI of 2007.

As claimed by Dator-Bercilla (2009), the Philippines may be relentlessly attempting to maintain gender equality and equity, yet efforts may not be enough to facilitate transformative process that will produce equality and equity between women and men in the Philippines. In support, magna carta of Women (RA 9710) institutes that all government agencies shall develop and make available information, education and communication materials on their specific programs, services, and funding outlays on women empowerment and gender equality. To this effect, education sectors specifically the Department of Education (DepEd), Commission on Higher Education (CHED), and Technical Education and Skills Development (TESDA) shall among others develop and promote gender-sensitive curriculum and develop gender-fair instructional materials. In the same line, Gender Equality Guide (2013) provided a checklist for gender equality in the education system which includes:

$>\quad$ review of the formulation of courses for possible gender-bias;

$>\quad$ analysis of gender biases in the theories and perspectives discussed in the course content;

$>\quad$ analysis of gender biases in assessments;

$>\quad$ review of activities for possible gender biases; and

$>$ review of reading materials, instructional and curriculum materials and textbooks; and review of class policies for possible gender biases

In support to the checklist provided are the ideas of Herz and Sperking (2004) that provided a simple formula for improving gender equality in education: making girls' education affordable, making education a practical reality, making schools more girl-friendly, and improving education quality. Further, UNESCO developed a Gender Equality Framework that describes four dimensions of gender equality in education equality of access, equality in the learning process, equality of educational outcomes and equality of external results - reinforcing the need to bring gender equality to, within, and through education (Herz, 2006). UNGEI's (2009) three-section program is believed to overcome gender disparities where area one is focused on enhancing access and participation of marginalized groups which included recommendations such as:

building schools at a safe walking distance;

$>$ placing community at the center if action;

$>$ expanding outreach through alternate modes of schooling; and expanding opportunities for secondary schooling

The second area features improving school equality with a gender perspective which includes inequitable practices within schools such as teacher attention, expectations and valuing, differential treatment within the classroom; and often unequal access to school spaces, resource and facilities. This also includes creating child-friendly/girl friendly school environments and overcoming systematics biases in the teaching-learning process. Finally, the third area focuses on improving learning outcomes which highlight consideration of boys' learning needs, confronting child labor and ensuring the school-to-work transition work for girls. 


\subsection{Gender Equality in Education Quality}

Reports in the study of Mesa (2007) stressed that culture and gender gaps which flourished in the region and the provinces were measured as educational disparities between sexes and between the poor and non-poor provinces. It was particularly noted that quality of education is beyond the scope of Mesa's paper which conforms to the initial claims of UNESCO (2012) that major researches in gender equality feature quantitative gender parity or disparity in national and regional levels. Additionally, UNESCO 2012 reported that some indicators like percentage of repeaters and survival rates do not contribute largely on the success or failure in achieving gender equality and even to the teaching and learning process though these indicators can provide information on education outcomes. To note, UNESCO (2012) claimed that educational outcomes and processes should be emphasized in ensuring that gender equality through good-quality education for girls and boys is achieved. UNESCO further stressed that assessing education quality is based on the capacity of instruction and in promoting the desired values and norms. As such, linking gender equality and education quality demands access to good - quality education and full educational accomplishment in basic education in order to eradicate barriers to school enrolment and in teaching modes and methodologies that prevent true gender equality. Thus, good quality instruction is needed to ensure gender sensitivity in learning opportunities in which boys and girls are given fair treatment and appreciation in order to acquire the desired learning outcomes.

As pointed out by EFA Global Monitoring Report 2008 (UNESCO, 2007), teaching can be gender bias. In many countries UNESCO reported that boys are more active and participative in classroom interactions and they get more attention. However, girls in majority of countries are better in literary skills than boys. Interestingly, Mullis, Martin, Fierros, Goldberg, and Stemler (2000) presented in the TIMSS Gender Report that there are few gender differences in the average mathematics and science achievement at the fourth and eighth grades. At the final year of secondary schools, males have significantly higher achievement both in mathematics and science (Mullis, et al., 2000). Likewise, the Philippines share the same dilemma where the low performance and high drop-out rate of boys attributed to child labor poses a real challenge towards achieving gender equality by 2015 .

According to UIS data from 2007, boys mostly drop-out of primary school and that the relative access to education of boys and girls is missed in both levels (primary and secondary) of education (CPI of 1.20 in GER for 2008). In connection to these findings, EFA GMR in 2008 showed the difference on the teachers' expectation on learning outcomes and students' behavior according to gender. For instance, if a teacher observes that most female students have low performance in mathematics, all student interactions will lean towards by this conviction. This means that the learning and teaching process gear towards the gender stereotyping of girls and their right to participate in quality learning. Hence, it is also worthwhile to take note of the interaction between the teachers and the students besides giving importance on the school infrastructures accessible and safe for both male and female students. In their interface with students, teachers have to make sure those boys and girls are appreciated by them and the students as well. This can also be done by considering the individual and gender needs of the learners in order to attain quality education because these needs can address values and equity in the milieu of education and the learning/teaching processes at the classroom level. It is also important to guarantee the learning materials, curricula and methodologies in teaching are gender sensitive in order to promote gender equality in learning and teaching. In other words, the aim of gender education is to promote changes in broader social and cultural issues and structures thus, gender equality in education is connected to gender equality through education.

Education requires equality among its structures which likewise can be evident to fairness and indiscrimination among female students. As such, the remaining challenge for EFA Goal 5 is the gender ideologies both in education and the society and not only on learning and accessibility to it (UIS, 2010). However, there are some issues on the qualitative aspect of learning process that are not emphasized while the monitoring progress towards the achievement of Goal 5 is mostly focused on quantitative aspects of achieving gender parity, qualitative issues in learning processes are often overlooked. In this tone, it is important to address the monitoring and evaluation mechanisms in order to look into the qualitative issues in teaching and learning. 


\section{Methodology}

Mixed method was utilized in the study. Quantitative research design combined with qualitative approaches was used in exploring the gender equality in education quality specifically in the aspects of instructional language, classroom materials and teaching aids, textbooks, curriculum, activities and interactions, and classroom management. Classroom observations, interviews with the students, post conferences with the teacher-participants, and focus-group-discussions with faculty and heads of the school participant were done to gather pertinent data to explore gender equality in education quality. The study consisted of two major stages: lived teaching-learning process and views, beliefs and perspectives on gender equality in education quality of teachers, student and school heads.

\subsection{Participants of the Study}

\section{Table 1}

Participants of the Study

\begin{tabular}{cll}
\hline Stages of the Study & \multicolumn{1}{c}{ Participants/Sample } & \multicolumn{1}{c}{ Sampling Process } \\
\hline & 3 schools identified from the identified & Simple Random sampling \\
& regions of the country & \\
& 12 math and science classes in 3 school & Convenient sampling \\
& participants & \\
Lived teaching-learning process & Grade 8 Math Classes per school participant & \\
& Grade 8 Science Classes per school participant & \\
& Grade 10 Math Classes per school participant & \\
& Grade 10 Science Classes per school & \\
& participant & \\
& 12 teacher-participants & Convenient sampling \\
& 15 student-participants & \\
\hline
\end{tabular}

In this two-stage study, simple random and convenient sampling was done to identify the appropriate participants for each of the stages identified. In the lived teaching-learning process, schools were identified through layers of simple random sampling. Random sampling by region, where three regions (Regions 2, 4A and 9) were identified to which provincial sampling was done. Schools identified per region were Cagayan National High School of Region 2, Mindoro National High School of Region 4A and Enfant Cheri Child Study Centre in Butuan City, Region 8. In each of the identified schools, researchers used convenient sampling to identify grade 8 (K to 12 framework) and $4^{\text {th }}$ year (old curriculum) science and math class-participants which resulted to 12 class-participants for the $1^{\text {st }}$ stage of the study. For the second stage, researchers used convenient sampling in the identified school-participants to determine the students, teachers, and school head-participants. The four teachers who taught the 4 identified classes of the school participant formed the teacher-participants, while chosen about 5 students from the observed classes were picked to form the student participants. School heads and/or department heads were requested-participants for focus-group-discussions. About 12 teacher-participants, 15 student-participants and 3 school head/department head-participant comprised the participants of the $2^{\text {nd }}$ stage of the study.

\subsection{Research Instrument}

The study utilized the research instrument titled Observation Protocol for Gender Equity in Classroom (OPGEC) which was developed by Morales and Espinosa and was published in the Research Journal of Social Sciences in 2015. The OPGEC is in the form of a modified semantic differential scale (1=not applicable; $2=$ don't know; $3=$ not at all; 4, 5 and $6=$ degree of agreement or disagreement; $7=$ to a great extent). The instrument has a Kappa coefficient of 0.83 and a single and average intra-class coefficient of 0.70 and 0.93 respectively. In addition, the reliability coefficient Cronbach's alpha of the instrument is 0.935 . Statistical tests show that the 
Exploring gender disparities in science and mathematics classrooms in the basic education

instrument is valid and reliable. After subjecting the OPGEC to factor analysis, the final instrument yielded eight constructs anchored on the $21^{\text {st }}$ Century Learning Framework: (1) Instruction and assessment (learning actuators, expanding literacies, climate of assessment and transparency); (2) Classroom management and environment (changing habits and roles); (3) Teacher and student interaction (mentoring and community); (4) Medium of instruction (mentoring community); (5) Teaching strategy (self-initiated transfer and thought and abstraction); (6) Loco parentis (changing habits and roles); (7) Instructional material (climate and assessment; and (8) Verbal teacher response (changing habits and roles). Table 2 shows the final OPGEC.

\section{Table 2}

Observation Protocol for Gender Equity in Classroom (Morales \& Espinosa, 2015)

Factor 1: Instruction and Assessment (Learning Actuators, Expanding Literacies, Climate of Assessment and Transparency)

B5: Expects equal academic achievement between males and females

B6: Invites both male and female visitors with non-traditional occupations into the classroom.

Factor 2: Classroom Management/Environment (Changing Habits and Changing Roles)

C13: Practices gender-neutral reading of, and writing on, students' work

C15: Doesn't ignore sexist remarks made by the students, but challenges them to be gender sensitive instead

Factor 3: Teacher-Student Interaction (Mentoring and Community)

C2: Provides more consideration, acclamation, and constructive feedback to males than with females

C3: Calls male students by name and asks them more often with complex and abstract questions than female students

Factor 4: Medium of Instruction (Mentoring and Community)

B3: Balances questions between males and females during class discussions and observes wait-time

C10: Stereotypes in the language being used.

Factor 5: Teaching Strategy (Self-Initiated Transfer and Thought \& Abstraction)

B1: Encourages cooperative learning in cross-gender groupings by mixing the seating arrangement among males and females and by avoiding dividing students into a single-gender activity groups.

Factor 6: In Loco Parentis (Changing Habits and Changing Roles)

B4: Gives equal help and in-depth guidance to females as well as with males

B5: Expects equal academic achievement between males and females

Factor 7: Instructional Material (Climate of Assessment)

B13: Ensures that books, computer programs, and other curriculum materials are free from stereotyped gender-role behavior

Factor 8: Verbal Teacher Response (Changing Habits and Changing Roles)

C1: Uses "effort-appreciation" statements more often with male than female students.

\subsection{Summary of Data Collection Methods Used}

\section{Table 3}

Summary of the Methodology

\begin{tabular}{llll}
\hline \multicolumn{1}{c}{ Stages of the Study } & \multicolumn{1}{c}{ Data Collection } & \multicolumn{1}{c}{ Instruments Used } & \multicolumn{1}{c}{ Data Analysis } \\
\hline Lived & Classroom observation & Gender Equity Classroom & Frequency and averages \\
teaching-learning & Video recording & Observation Protocol & Polarity profile factors \\
process & & Gender Equity Form & Transcriptions \\
$\begin{array}{l}\text { Views, beliefs and } \\
\text { perspectives }\end{array}$ & Audio recording & Interview protocol for & Transcriptions \\
& & teachers and students & Coding \\
& & Focus-group-discussion & \\
& & protocol & \\
\hline
\end{tabular}

\subsection{Data Collection}

Stage 1: Lived Teaching and Learning Process - Preliminary consultation with the teachers of the classes to be observed was done to check on the class statistics such as number of males and females and if there were members of specific minor or major ethnic groups. Field researchers observed grades 8 and 10 science and math classes. During observations, classroom observation protocol and gender equity form were accomplished. Video 
Morales, M. P. E., Avilla, R. A., \& Espinosa, A. A.

recording of the whole lesson was also done to capture all necessary parts of the teaching and learning process. The observation proceedings were conducted with a focus on determining gender and culture gaps

Stage 2: Views, beliefs and perspectives - With the intention to verify and further explore those observed in the lived teaching and learning process, field researchers conducted interviews with teachers of the observed classes, selected students of the observed classes and school heads of the selected schools. As guide, they used the developed Interview and focus-group-discussion protocols. Focus-group-discussion was done with the other teachers of the math and science departments who were not observed I the lived teaching and learning process to ensure that their ideas and concepts of gender and culture gaps in science and math education were also extracted.

\subsection{Data Analysis}

Analysis of data gathered from the stage 1: lived teaching and learning process included frequencies, averages, standard deviations, transcriptions of video-taped lessons and coding scheme to determine key terms, common ideas, and other valuable information pertinent to the study. Analysis of information gathered from the second stage: views, beliefs and perspectives encompassed transcriptions of interviews and focus-group-discussion and coding system to define key terms, common ideas, and other valuable information relevant to the study. A modified polarity profile was constructed using the mean ratings to have a clear view of how a certain domain in the OPGEC is strongly or weakly or not at all manifested in mathematics and science classes.

\section{Results and Discussion:}

Factor 1: Instruction and Assessment (Learning Actuators, Expanding Literacies, Climate of Assessment and Transparency)

Shown in Table 4 are the mean and standard deviation of the statements in factor 1 while shown in Figure 1 is the modified polarity profile for the same factor.

\section{Table 4}

Descriptive statistics for factor 2

\begin{tabular}{lcc}
\hline & MEAN & SD \\
\hline B7 & 3.9167 & 2.06522 \\
B10 & 3.9167 & 1.88092 \\
B11 & 3.6667 & 2.46183 \\
B12 & 3.3333 & 2.34844 \\
C13 & 3.3333 & 2.38683 \\
C15 & 1.4545 & 1.43970 \\
C17 & 4.3636 & 1.20605 \\
C18 & 5.1667 & .71774 \\
C19 & 4.1667 & 1.33712 \\
C20 & 3.4545 & 2.16165 \\
\hline Ave & 3.5248 & 1.82277 \\
\hline
\end{tabular}

Seemingly, most statements fall between 1 (Not Applicable) and 3 (Not at All) and only five items fall near or beyond 5 (the midpoint between not at all and to a great extent). In domains B6, B8, B9, B14 and C11, most observers agree that they do not know whether the situation transpired or not. Below are statements B6, B8, B9, B14 and C11:

B6: Invites both male and female visitors with non-traditional occupations into the classroom.

$B 8$ : Initiates or discusses gender concerns with students when gender issues arise.

B9: Encourages physical activity in on-traditional gender roles (e.g. encourages females to play football or 
males to do handclapping games.)

B14: Exposes stereotyped gender-role behavior when encountered in curriculum materials

C11: Uses degendering terms as "police officer and "fire-fighter" rather than "policeman and fireman."

Further analysis of the interview with students and the focus group discussion with teachers contradicts the observation report, below are selected transcribed videos and unedited responses of students and teachers.

Teacher 5: I give equal chances to all in class activities. I use "neutral" names in exams like he/she. In choosing materials, I choose those that are not discriminating to any sex (like using balls only to explain projectile motion).

This was also observed in the class of Teacher 5 where he made use of "shooting a crumpled paper in a basket" activity to demonstrate and teach projectile motion to students. Shooting activity was not only limited to "boys" shooting the paper but also girls. This activity was done in mixed groups where boys and girls are members of a team or a group. Furthermore, teachers from Mindoro claimed that mathematics problem solving or board work activities were not attributed to male students only. They said "regardless of gender naman po, kahit sino" which means that they are not particular with gender when it comes to mathematics or science activities. In another class, the teacher asked the students to run in the oval and had a race to explain motion. But the teacher emphasized that she would need to separate the boys from the girls although everyone is asked to do the activity. These observations noted in the transcribed videos show that most teachers are not particular with gender - activity or capability relation. They treat students fair and equal that contradicts with statements C22 and $\mathrm{C} 23$ as presented below:

C22: Expects that graphical skills and computations are attributed to males.

C23: Expects that essays and oral discourse are attributed to females.

In an interview with students, some girls noted that they also liked solving mathematical problems. While most boys expressed that they enjoyed group activities and that they wanted to be grouped with female classmates because most boys tend to listen to the suggestions of their female group mates when doing certain task. Furthermore, teachers claim that there are sections where many male students are more active in Math than their female classmates but there are other sections where female students are better in Math than their male classmates. Thus, according to their teachers, being good in Math is not a matter of gender. Jenkins (2006) identified factors related to positive attitude towards Mathematics as teacher's attitude and parent's attitudinal influence in Mathematics. He reported that positive attitude of teacher to Mathematics is often translated to a positive attitude of students to the subject. In the same manner, parents who show interest to the subject are often identified to have children who are interested in Mathematics more than other students. Thus, quality education for both gender also covers teacher interest and influence domain which agrees with the reports and recommendations of OECD (2011) which includes encouraging parents and teachers to raise self-confidence and motivation among girls to pursue interests in science and mathematics and target at attaining better balance in the gender composition of teachers and the endorsement of female role models in professions typically dominated by men might also contribute to this objective. The need for female role models was also noted as the expressed desire of many students. Below are some unedited statements of students in an interview:

Student 3: I mostly like female teacher because they are like my mother. It is also easy to understand explanations of female teachers.

Student 6: I would rather choose a female teacher than a male teacher. For female teacher has a longer patience than a male teacher based from my observations as a student.

Student 8: Female teacher because they easily get along with their students, comfortable to be with and they know best plus they are not scary and they are really patient with their students.

Furthermore, the video transcriptions conform to the observations noted in the domains of B5, C8, C21 and $\mathrm{C} 22$, where an apparent manifestations of such perceptions in the classrooms. Below are the statements of the said domains:

B5: Expects equal academic achievement between males and females. 
Morales, M. P. E., Avilla, R. A., \& Espinosa, A. A.

C8: Gives everyone an equal opportunity in all activities.

C21: Judges academic achievement of students not based on gender expectations, but rather with the results of equal treatment and evaluation using the same benchmarks or evaluation tools.

C22: Lets equal goals and try to have all students meet similar achievements (e.g. males should not be expected to do better on science experiments or projects that require hands-on construction and girls should not be expected to do better on written assignments and art project).

Analysis of the interview with students and teachers agree with the noted perceptions observed in the different science and mathematics classes as shown in the interview with students and the focus group discussion with teachers below:

Teacher 9: Both male and female should be given an equal opportunity for self-expression and the freedom to choose certain preferences. They should be given the opportunity to be assessed accordingly and that rubric and criterion must be used in assessing performance of student to avoid subjective judgment.

Teacher 10: Equal attention and equal treatment should be given to both genders. Rules in the classroom should be given. Same tools will be given to each student. Test materials are common and instructions used are the same to all regardless of gender and culture.

Student 8: For me, I believe that all of us in our class can participate or can do. Because all of us have the capacity to share what we want. I also believe that our teacher give the same degree of difficulty because she does not have favoritism in our class. She believes that we can solve all the problems she will give us.

In all the above transcripts, it seems that quality education is targeted to both genders. However, most teachers agree that there are few boys going to school than girls. Thus, although quality is assured to both genders, the problem of gender parity still exist which is attributed to social functions and roles ascribed to males. Even at early age they seek out the labor market to help in alleviating their families from poverty. According to GER (2008), the Philippines' low performance and drop-out rate among male students is highly related to child labor wherein most child workers from are males from total areas. UIS (2007) reported that there are two out of five working children between 5 and 17 years old are leaving school and the gender parity in enrolment lacks in almost all levels of education.

Factor 2: Classroom Management/Environment (Changing Habits and Changing Roles)

Table 5 shows the mean and standard deviation of the statements in factor 1 while shown in Figure 2 is the modified polarity profile for the same factor.

\section{Table 5}

Descriptive statistics for factor 2

\begin{tabular}{lcc}
\hline & $M E A N$ & $S D$ \\
\hline B7 & 3.9167 & 2.06522 \\
B10 & 3.9167 & 1.88092 \\
B11 & 3.6667 & 2.46183 \\
B12 & 3.3333 & 2.34844 \\
C13 & 3.3333 & 2.38683 \\
C15 & 1.4545 & 1.43970 \\
C16 & 2.0000 & 2.04495 \\
C17 & 4.3636 & 1.20605 \\
C18 & 5.1667 & .71774 \\
C19 & 4.1667 & 1.33712 \\
C20 & 3.4545 & 2.16165 \\
\hline Ave & 3.5248 & 1.82277 \\
\hline
\end{tabular}

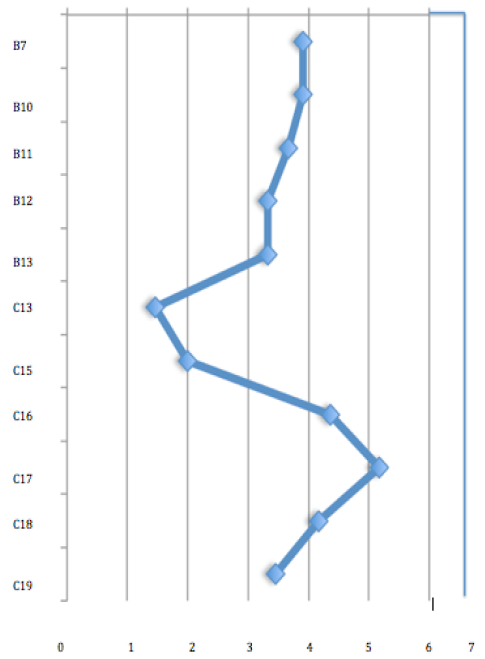

Figure 2.Polarity profile for factor 2

Accordingly, nine out of 12 statements fall between 1 (Not Applicable) and 3 (Not at All) and only three items fall near 5 (the midpoint between not at all and to a great extent). In B12, and B13; most observers agree that they do not know whether the situation transpired or not. Below are statements B12 and B13: 
B12: Balances other assigned classroom jobs (e.g. lifting or moving chairs and desks, cleanup, running errands) between both genders.

B13: Ensures that books, computer programs, and other curriculum materials are free from stereotyped gender-role behavior.

Further analysis of the interview with students and the focus group discussion with teachers support the observation report, below are selected unedited responses of students:

Teacher 1: I tend to recognize one's difference in choosing a strategy

Teacher 2: I assign task in accordance with what they can perform

Student 1: No, because some of the activities can't do the girls like lifting heavy objects so the boys do them.

Student 2: Girls are assigned to clean the room while boys are assigned to clean the ground.

Student 3: For my boy classmates, yes because all of us are physically fit and for girls, no because some of them can't do what we can do physically because of their capacity to do physical activities.

Student 4: No, for the physical activities the degree of difficulty our teachers give easier for the girls.

The above analysis agrees with EFA Global Monitoring Report 2008 (UNESCO, 2007) that boys are more active and participative in classroom interactions and they get more attention. The same was observed by several teachers who were interviewed about how do their male students differ in terms of school performance with their female counterparts. They claimed that usually male students are good in analysis and numbers while female students are good in writing and oral discourse. On the other hand, some teachers claim that females are the achievers in class but they also reasoned that this is because of the fact that there are a lot more female enrollees in the class than males. They claimed that many males tend to drop out due to family concerns which match the initial findings of UIS (2007), boys mostly drop-out of primary school and that gender parity in enrolment is not observed both in the primary and secondary levels of education (CPI of 1.20 in GER for 2008). However, most of the FGD and interview with the participants do not agree with the observation report, below are selected unedited responses of students and teachers.

Student 1: For me, I believe that all of us in our class can participate or can do. Because all of us have the capacity to share what we want.

Student 2: Yes, we are given equal opportunity to perform or work in the classroom.

Student 3: Yes because we have the same capacity but sometimes do not participate in classroom jobs

because they have menstrual period.

Teacher 1: Jobs are assigned regardless of gender.

Teacher 2: Equal treatment and attention will be given to both genders.

In domains B7, B10, and B11, observers somehow agree that the situation is observed or manifested in the classroom. Below are statements B7, B10 and B11:

B7: Disciplines males and female students in the same manner and frequency.

B10: Constructs test questions in a gender-neutral fashion.

B11: Balances or assigns leadership roles and support positions for both males and females.

Analysis of the interview with students and the focus group discussion with teachers support the observation report. Below are selected unedited responses of students and teachers:

Student 1: All I am trying to say is that the teacher has no favoritism and gives the same difficulty in all tasks especially in tests.

Teacher 1: Both genders are given equal chances of holding a position in class organization and they are also given the same disciplinary actions.

Teacher 2: House rules are the same for all students

Teacher 3: Test and materials are all the same for both male and female students.

However, the scripts shown above contradict claims of other teachers like:

Teacher 1: Madalas madisiplina ay ang lalaki kasi hindi naglilinis. Kase sa bahay e dapat ang Mother ang gumagawa. Ang father pinagsisilbhan yun ang traditional at yun Kanilang naa-dopt. (The males are often given disciplinary action because they refuse to clean. They think that the females are the one who should clean because at home they are used to the tradition that the mother does the household chores which the 
Morales, M. P. E., Avilla, R. A., \& Espinosa, A. A.

students then to adopt even when they are in school.)

The above analyses relate to the interpretation of Rayaprol (2010) that teachers must not ask boys to solve the sums because they are "naturally" good at math or the girls to help with the cleaning up of the classroom as they are expected to be more inclined to do housework. This goes with domain C17 (Exhibits instructional styles that match the male and female's student learning styles). As shown in the polarity profile of factor 2, observers agree that the statement is manifested in the classroom which falls near 5 (the midpoint between not at all and to a great extent) as presented in the interviews below:

Teacher 5: Pagdating sa klase fair naman ako kaso lang kalimitan pagdating sa Math Nakikita natin talaga magagaling naman ay lalaki kaso lang tamad hindi katulad ng girls maasahan talaga. (In classroom, I consider myself as a fair teacher, however, more often than not, the usual observation is that boys are really good in Math but are not that studious and diligent compared to girls.)

Teacher 6: Girls are better in Natural sciences and boys in math.

Teacher 7: When it comes to language and comprehension, boys do have hard time while girls are not that analytical especially in numbers. So problems solving are better with boys and writing or discussion for girls.

Though some teachers claim that their teaching styles are influenced by students' learning styles they also exert effort in adopting a fair classroom environment. Observers noted a near agreement in domains $\mathrm{C} 16$ and C18. Below are statement $\mathrm{C} 16$ and $\mathrm{C} 18$ :

C16: Discusses fair and unfair gender-related treatments with students and help them analyze and think about their own behavior.

C18: Gives ample opportunities to students to participate in both methods of learning (collaborative and peer challenge).

Teacher 7: Depende sa activity. Yes...just like last month. I have my activity on motion. So I let them run in the oval, we would have a race. They love games in physics.

Teacher 1: I usually inject in their mind that gender equity should be observed in the society. I also initiate activities which involve the participation of all genders.

Although some teachers claim that they let all students participate in all the different activities regardless of gender and that they allow collaboration or peer challenge to exist, they still modify activity setting or physical layout of class in order to promote gender equity which is contrary to the observers' views as presented in the polarity profile of factor 2 where domain $\mathrm{C} 19$ (Modifies activity settings and physical layout of class in order to promote gender equity.) is noted not to transpire in their observations. Below are some claims of teachers in the interview and FGDs that contradicts observers' remarks:

Teacher 8: Arrangement of students is alphabetical but we place the boys in front. However, we also consider other learner characteristics like height.

Teacher 9: Ganun talga yung arrangement, alphabetical pero nasa unahan ang boys. Kasi ang purpose naman non kasi dib a mas magulo ang lalake. Kung nasa likod sila mas lalaong ano amgulo. Kung nasa unahan sila medyo iba-iba kase ang lapit lang sa teacher. (The usual seating arrangement of students is alphabetical arrangement and boys are seated in front because of behavior reasons. They are usually more active than girls and being seated in front allows them to be nearer to the teacher which makes them behave better.)

Finally, in $\mathrm{C} 13$ and $\mathrm{C} 15$; most observers agree that they do not know whether the situation transpired or not. Below are statements $\mathrm{C} 13$ and $\mathrm{C} 15$ :

C13: Practice gender-neutral reading of, and writing on, students' work.

C15: Doesn't ignore sexist remarks made by the students, but challenges them to be gender sensitive instead.

Further analysis show that most teachers claim that they do their best to become gender sensitive and practice gender equity. In fact, they do not encounter any sexist remarks from the students thus, there is no need to challenge them to be gender sensitive as it is already in their system to be respectful of what others can and cannot do. Below are some verbatim comments of students: 
Student 4: Yes because everyone of us must have the right to learn and to do everything even if you're a girl or a boy. Every one of us has the equality of doing it.

Student 5: Yes because each of us has its own capability and ability.

Student 6: Yes because we have different abilities.

The analysis above shows that students are practically aware and sensitive to gender issues. Learning and achieving is not a matter of what their gender is but about hard work and diligence. They recognize their own capabilities and capacities and respect the competence of others in terms of gender and in terms of culture. This may highlight the report of Yoshida (2012) which featured that the impact of education can be rather more complex. Education may enlighten people about the problems of inequality and make them receptive to the possibility of reducing the gender gap. On the other hand, it may also be that education reproduces inequality. According to Kane (1995), education "may actually legitimate rather than challenge inequality" by emphasizing the importance of individual talent or effort in social accomplishment. However, equity does not imply treating all learners the same because many factors could disadvantage students in having a chance to achieve equitable outcomes. According to ILO (2010), responses may include "equal treatment or treatment that is different but which is considered equivalent in terms of rights, benefits, obligations and opportunities." World Bank (2005), conformed and mentioned that a basic principle of equity is equality of opportunity among people: "that a person's life achievements should be determined primarily by his or her talents and efforts, rather than by pre-determined circumstances such as race, gender, social or family background."

Factor 3: Teacher-Student Interaction (Mentoring and Community)

Table 6 shows the mean and standard deviation of the statements in factor 3. On the other hand, Figure 3 shows the modified polarity profile for the same factor.

\section{Table 6}

\begin{tabular}{lcc}
\multicolumn{3}{c}{ Descriptive statistics for factor 3} \\
\hline & MEAN & SD \\
\hline C2 & 2.5000 & 1.38170 \\
C3 & 2.6364 & 1.36182 \\
C4 & 2.0833 & 0.28868 \\
C5 & 2.5833 & 1.37895 \\
C6 & 2.3333 & 1.23091 \\
C7 & 4.8182 & 1.07872 \\
\hline Ave & 2.8258 & 1.12013 \\
\hline
\end{tabular}

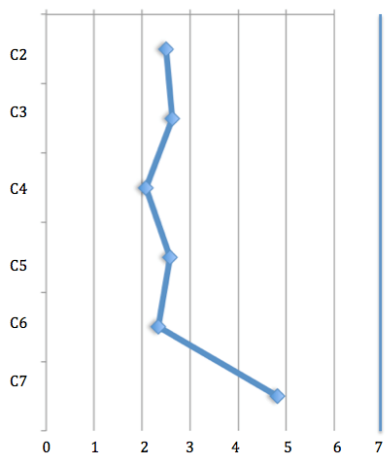

Figure 3. Polarity profile for factor 3

Apparently, most statements fall between 2 (don't know) and 3 (not at all) and only one statement fall near 5 (the midpoint between not at all and to a great extent). In domains $\mathrm{C} 4$ and $\mathrm{C} 6$, most observers agree that they do not know whether the situation transpired or not. Below are statements $\mathrm{C} 4$ and $\mathrm{C} 6$

C4: Shows those female students are prone to becoming the invisible and losing members of the classroom.

C6: Provides less academically valuable and more superficial feedback to female students.

Further analysis of the interview with students and the focus group discussion with teachers support the observation report. Below are selected unedited responses of students and teachers:

Teacher 2: Sa akin ay female. Kase, ang girls ay mas studious than the boys. Diba? Ay syempre na-experience ko rin yan. Na mas, nag-eexcel ay laging, majority sa aking hinahandle parang girls. Sa halimbawa, sa mga acting. (For me it's female because girls are more studious compared to boys, right? I felt that girls excel more especially in play.)

Student 2: I believe that every person is created equally with skills like mine but others are not for, I also believe that everybody has his/her own role in the community.

Student 5: As a girl, my favorite task is to participate in class discussions for me to be recognized. 
The analysis contradicts the UNESCO Report in 2007 that boys are more active and participative in classroom interactions and they get more attention than girls. In a Philippine science and mathematics classrooms, girls are also given equal opportunities and attention. Further analysis of the transcripts during the focus group discussions, teachers noticed that girls are actively participating in the class discussions and activities like problem solving and group dynamics. This is also because majority of the classes are outnumbered by girls. However, transcripts in the interviews conducted among students and teachers agree with the domains of $\mathrm{C} 2, \mathrm{C} 3$ and $\mathrm{C} 5$. Below are the statements in the said domains:

C2: Provides more consideration, acclamation, and constructive feedback to males than with females.

C3: Calls male students by name and asks them more often with complex and abstract questions than female students.

C5: Provides academically specific remediation, as well as praise and criticisms to male students.

Analysis of the interview with students and teachers agree with the noted perceptions as observed in the different science and mathematics classes. These responses agree in the study of Berekashvili (2012) that from the teacher's opinion, boys entirely outdo girls in natural sciences and math and that they totally deny girls' abilities in sports. This likewise supports the idea that gender determines different abilities in different learning skills as regards school subjects (Berekashvili, 2012). Below are some of the noted and unedited responses of the students and teachers:

Teacher 3: Male students participated well during discussions because they are more active and feeling free to express as they are.

Student 4: No, because our teacher knows that girls cannot do homework like lifting a heavy chair, or in MAPEH push up because ma can do this best.

Teacher 7: Well I guess boys are active when it comes to numbers. Even in my Physics class, boys are quite more active.

In the foregoing discussions, it is believed that gender is not a major issue in the teacher-student interaction inside a science and mathematics classroom. There is somehow equality among boys and girls when it comes to classroom interaction. This is evident when teachers are posing questions as observed during the lived classroom observation in which students regardless of gender are being called and recognized equally. However, the role of gender has effect on the patterns of teacher-student interactions. In the study of Rashidi and Naderi (2012) revealed that patterns of teacher-student interactions are gender related. They pointed out that male students initiated more exchanges with their teachers, while female preferred to be addressed by their teachers. Likewise, Rashidi and Naderi (2012) revealed that male students also made more humor and feedback to their teachers. These findings were also observed during the lived classroom observation when male students initiated humor in the class. These were also claimed by some of the teachers that male students are more active during discussion even the class is dominated by most female students.

Factor 4: Medium of Instruction (Mentoring and Community)

Table 7 shows the mean and standard deviation of the statements in factor 4. Figure 4, on the other hand, shows the modified polarity profile for the same factor.

Table 7

Descriptive statistics for factor 4

\begin{tabular}{lcc}
\hline & MEAN & SD \\
\hline B3 & 4.5833 & 1.62135 \\
C10 & 2.4545 & 0.93420 \\
\hline Ave & 3.5189 & 1.27778 \\
\hline
\end{tabular}

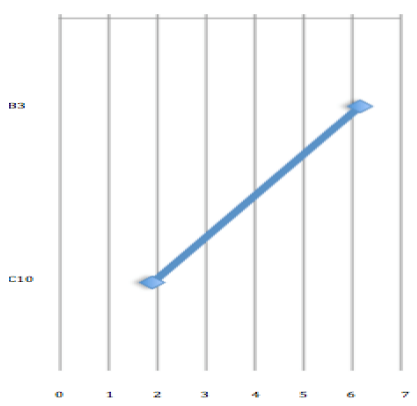

Figure 4. Polarity profile for factor 4

B3 falls under 2 (don't know) while C10 falls under 5 (which is very near the to a great extent scale. In domain B3, most observers agree that they do not know whether the situation transpired or not. On the other 
hand, they believe that C10 was observed to almost a great extent. Below are statements B3 and C10:

B3: Balances questions between males and females during class discussions and observes wait-time.

C10: Stereotypes in the language being used.

Analysis of the interview with students and the focus group discussion with teachers does not support the observation report in B3. Most of the students and teachers agree that questions asked during class discussions are balanced among males and females. Below are selected, unedited responses of students and teachers during the interview.

Teacher 4: "Both male and female should be given an equal opportunity for self-expression..."

Teacher 3: "Equal attention and equal treatment should be given to both gender."

Student 4: "Yes. If we have oral recitations, the teacher gives us the same questions."

Observers might have probably focused on the wait time in which they think they did not observe during classroom discussion. But then again, equity in the distribution of questions does exist. A documentary report by Quindlen (2009) agrees that both males and females are now given equal opportunity to be heard in the academe. Gone are the days of the traditional teachers who believe only in the capability of the male species.

In $\mathrm{C} 10$, observers agree that most science and mathematics teachers does stereotype in the language. Instances show that most of the examples of teachers are very masculine in nature. Notes from the observers show that during class discussions, no matter what the gender of the teacher is, they tend to use masculine nouns and activities. Francis and Skelton (2001) also noted the same observations. However, the masculine stereotyping did not hinder success in the schooling of the children.

Factor 5: Teaching Strategy (Self-Initiated Transfer and Thought \& Abstraction)

Shown in Table 8 are the mean and standard deviation of the statements in factor 5 while Figure 5 shows the modified polarity profile for the same factor.

\section{Table 8}

\begin{tabular}{ccc}
\multicolumn{3}{c}{ Descriptive statistics for factor 5} \\
\hline & MEAN & SD \\
\hline B1 & 3.8333 & 2.12489 \\
\hline
\end{tabular}

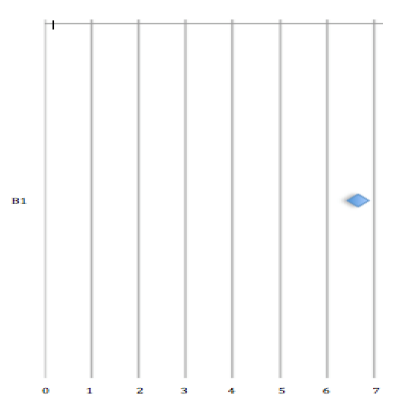

Figure 5. Polarity profile for factor 5

In this factor, only B1 statement is observed. Most of the observers agree that the situation is observed or manifested inside the classroom. Below is the statement of B1:

B1: Encourages cooperative learning in cross-gender groupings by mixing the seating arrangement among males and females and by avoiding dividing students into a single-gender activity groups.

Analysis of the interview with the students and the focus group discussions among the science and math teachers support the observation report. Below are some of the unedited responses of students and teachers:

Teacher 8: If may activity, kailangan, nire-require ko na by pairing na. So ang pinagpe-pair ko ay boy at girl. Kase para hindi magkaroon ng competition between the, halimbawa dalawang girls na pair tapos dalawang boys. (During activities, I required them to work in pairs. I paired boy and a girl. This is to avoid competitions between same gender pairs.)

Teacher 9: Halimbawa sa group, kailangan may male. Distributed yun male sa bawat group para dahil may rule syang sya lang makakagawa e. (There should be male students in a group. This is because there are rules in an activity that males can only do.)

Student 7: Yes, by dividing us into groups composed of boys and girls and letting us do work the work together. 
The analysis shows that students and teachers are aware that gender does not hinder the success of any classroom activity if asked to work in a group or pair. They knew the importance of each other's capabilities in order to finish the activity faster and successfully. This is also evident in a video transcript of the lived teaching in which one teacher grouped boys and girls together. This only implies that teachers recognized the value of each student regardless if male or female in doing any task However, Scantlebury (2009) explained that pairing girls and boys means that the teachers use gender expectations as a way of maintaining classroom control. This further implies that the teachers used the girls' nurturing role to those who needs assistance. Furthermore, it is likewise good to note that schools in the Philippines are regarded as second home of the students. According to one teacher during the FGD, she emphasized that in a group male students are distributed because there are activities that only boys can do. Furthermore, another teacher claimed that females should do the chores like cleaning the room because this is what mothers do in a typical Filipino home. This is what Scantlebury (2009) noted in her article in which teachers' unconscious gender biases can produce stereo-typic expectations for students' success and participation in the classroom.

Factor 6: In Loco Parentis (Changing Habits and Changing Roles)

Table 9 shows the mean and standard deviation of the statements in factor 6. On the other hand, Figure 6 shows the modified polarity profile for the same factor.

\section{Table 9}

Descriptive statistics for factor 6

\begin{tabular}{lcc}
\hline & MEAN & SD \\
\hline B4 & 4.4167 & 1.62135 \\
B5 & 4.0000 & 2.33550 \\
B14 & 1.9167 & 1.72986 \\
\hline Ave & 3.4444 & 1.89557 \\
\hline
\end{tabular}

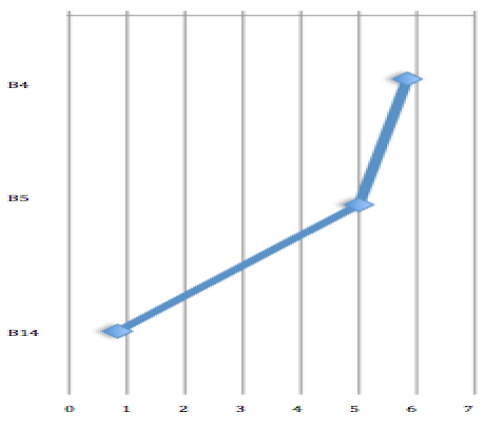

Figure 6. Polarity profile for factor 6

Accordingly, there are two statements that fall near 5 (the midpoint between not at all and to a great extent) and one statement falls between 1 (Not Applicable) and 3 (Not at All). In domains B4 and B5, most observers agree that the situation is observed or manifested inside the classroom. Below are the statements B4 and B5:

B4: Gives equal help and in-depth guidance to females as well as with males.

B5: Expects equal academic achievement between males and females.

Analysis of the interview with students and FGD with the teachers support the observations report. The following are some of the unedited responses from the students and teachers:

Teacher 1: Fair treatment for students regardless of gender.

Teacher 3: Display treatment to students regardless of gender and also social status.

Student 3: Yes, example in an examination if a girl does complain about an item the teacher will hear her opinion so does the teacher if a boy complains. All I'm trying to say is the teacher has no favoritism and also if that would be if the class will hate the teacher.

Student 2: Yes, giving all of us equal questions which we also can answer.

The analysis indicates that the students are getting fair treatment in terms of attention, opportunities and activities inside a classroom. This further implies that the teachers are devising varied methods and strategies in their teaching of science and mathematics. This is observed during the actual classroom observation in which one science teacher asked her class to perform the projectile motion activity not only for the male students as well as for the female students. Similarly, a Math teacher called her male and female students to solve the same problem. The teacher also directed the male students to interact with the female students and so as female students to the male students. This somehow contributed to the equality of opportunities and activities between 
genders. However, Scantlebury (2009) cautioned teachers to prepare for some consequences of changing practices inside classroom for this might cause disciplinary problems.

On the other hand, in domain B14, most observers agree that they do not know whether the situation transpired or not. Below is the statement B14:

B14: Allows adequate wait-time for problem-solving activities.

Allowing wait-time is becoming significant. Rowe (1986) explains the effects of wait-time on students and teachers. She further explains that wait time can increase the student-student exchanges and the teacher-centered "show and tell" decreases. Rowe (1986) described that discourse between students and even to the teachers begins to show more coherence under a 3-second wait-time. Longer wait-time also gives opportunities for other students to participate actively. The video transcript analysis revealed that the teacher somehow allows the wait-time when asking questions and did the follow-up questions. It was noted that regardless of male and females students, the students are raising their hands to answer the questions by posed by the teacher. This is observed when a student made a remark, our teacher makes sure that all of us understood the lesson and will ask us one by one. However, there was limited evidence on the possible difference on wait-time between male and female students.

Factor 7: Instructional Material (Climate of Assessment)

Table 10 gives the mean and standard deviation for factor 7 . Figure 7, on the other hand gives the modified polarity profile for the same factor.

Table 10

Descriptive statistics for factor 7

\begin{tabular}{lcc}
\hline & MEAN & SD \\
\hline B13 & 1.9167 & 1.83196 \\
\hline
\end{tabular}

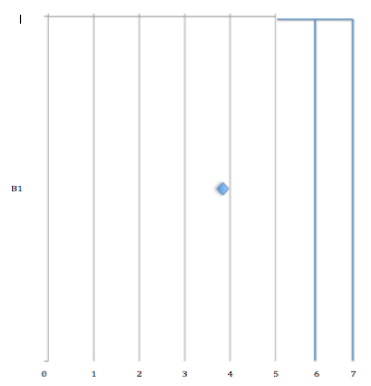

Figure 7. Polarity profile for factor 7

B1 falls under 4 (near not at all). Observers believe that B1 was almost not at practiced at all in the teaching and learning process. B1 states "Ensures that books, computer programs, and other curriculum materials are free from stereotyped gender-role behavior". Experiences of observers show that there really are biases in terms of gender most especially in books. Although no particular instance where teachers or students mentioned this disparity during the interview, the observers can attest that there really was. Studies show that most characters or roles depicted in most books are very masculine - nouns and pronouns are geared toward the male gender. However, just like most studies, it does not affect achievement in the subject (Whiteley, 1996).

Factor 8: Verbal Teacher Response (Changing Habits and Changing Roles)

Table 11 shows the mean and standard deviation for factor 8 . Figure 8 , on the other hand, shows the modified polarity profile for the same factor.

Table 11

Descriptive statistics for factor 8

\begin{tabular}{lcc}
\hline & MEAN & SD \\
\hline $\mathrm{C} 1$ & 2.8333 & 1.40346 \\
\hline
\end{tabular}

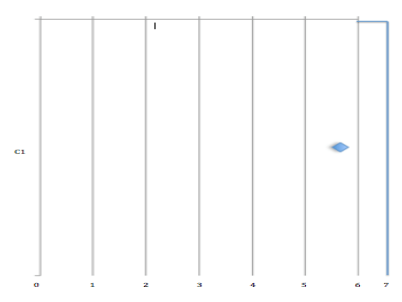

Figure $8 . \quad$ Polarity profile for factor 8 
Morales, M. P. E., Avilla, R. A., \& Espinosa, A. A.

Statement $\mathrm{C} 1$ falls under 3 or not at all. C1 says "Uses effort-appreciation statements more often with male than with female students". It shows that teachers give positive reinforcement to both gender no matter what the situation is. It was also observed from the interviews with teachers and students. Below are selected unedited responses:

Teacher 5: "Equal attention and treatment will be given to the students regardless of their gender."

Student 8: "Yes, we are all treated equally."

Studies show that gender bias might be present in the past but in the present academic institutions, both sexes are now given equal opportunity (Zadker \& Zittleman, 2009).

\section{Conclusion and Recommendations}

Analysis of the observation reports and transcripts, gender biases in the science and mathematics classrooms can still be observed. Though students and teachers strongly agree, believe or claim that equality in sexes must be maintained at all times inside the classroom because in some aspects, it affects academic achievement and a healthy environment; still evidences were gathered to note that inequality in terms of quality persists. In all the factors presented, inequality in quality is mostly observed in factors 1,2 , and 3 which are on the areas of instruction and assessment, classroom management and environment, and teacher-student interaction. Most of these inequalities were observed to be highly influenced by the traditions, practices, beliefs and culture of the place or province. Although gender inequality in quality education exists in the country, cultural biases were not observed which emphasizes that most Filipinos tolerate different cultures and their practices and beliefs. Students as well as teachers are accustomed to multi-cultural setting and environment which started good collaboration for provision of education to the minorities and help the country achieve its major goal of education for all (EFA). While most students and teachers believed in equality in quality, this belief must be translated to action to enhance the quality of education provided to both genders. The study may then be an input data to policy makers and government agencies servicing education of the Filipino citizens. The study might have a different result for other cultural groups, it is therefore recommended that the instrument as well as the interview protocols be applied or used to other cultural groups in the Philippines and beyond for more conclusive results for the Philippines and other countries as well.

\section{References}

Al-Rodhan, N. R. F., \& Stoudmann, G. (2006). Definitions of globalization: A comprehensive overview and a proposed definition. Program on the Geopolitical Implications of Globalization and Transnational Security: 6.

Balisacan, A., \& Fuwa, N. (2004). Changes in spatial income inequality in the Philippines. Research Paper No. 2004/34.World Institute for Development Economics Research.

Balisacan, A., \& Piza, S. (2003). Nature and causes of income inequality in the Philippines. Background Paper for the EADN Income Distribution Project.

Berekashvili, N. (2012). The role of gender-biased in teacher-student interaction. Retrieved from http://www.degruyter.com/view/j/plc.2012.16.issue-1

Cruz, L. (2007). Philippine gender gap index status of Philippine women in Science. Retrieved from http://www.asiainnova.es/pdf/cruz.pdf

Dator-Bercilla, J. (2009). Facing the continuing challenge of gender inequality and inequity. Retrieved from http://www.socialwatch.org/sites/default/files/pdf/en/09_missingtargets.pdf

East Asia Pacific Regional UNGEI. (2009). Retrieved from http://www.ungei.org

East Asia Pacific Regional UNGEI. (2010). Retrieved from http://www.ungei.org

Francis, B., \& Skelton, C. (2001). Men teachers and the construction of heterosexual masculinity in the classroom. Sex Education: Sexuality, Society and Learning 1(1), 9-21.

Gender Equality Guide. (2013). Retrieved from 
Exploring gender disparities in science and mathematics classrooms in the basic education

http://pcoo.gov.ph/genderfairmedia/buk3_gender_equality_guide.pdf

Herz, B. (2006). Educating girls in South Asia: promising approaches, UNGEI series UNICEF ROSA. Retrieved from http://www.unicef.org/rosa/education_2483.htm

Herz, B., \& Sperking, G. (2004). What works in girls' education: evidence and policies from the developing world. Council on Foreign Relation. Retrieved from http://www.cfr.org

ILO. (2010). Women in labour market: measuring progress and identifying challenges. ILO, Geneva.

Jenkins, N. (2006). Factors that influence mathematics attitude. Retrieved from http://scimath.unl.edu/MIM/files/research/JenkinsN.pdf

Kane, E. (1995). Education and beliefs about gender inequality. Social Problems 42(1), 74-90.

Manahan, M. (2010). Focus on women and men in the Philippines ---closing the gender gap. Retrieved from http://www.focusweb.org/philippines/fob-articles/socio-economic-monitor/391-focus-on-women-and-m en-in-the-Philillines-closing-the-gender-gap

Mesa, E. (2007). Measuring education inequality in the Philippines. Philippine Review of Economics, 44(2), 33-70.

Morales, M., \& Espinosa, A. (2015). Development and validation of observation protocol for gender equity in classroom: towards achieving gender equality in education. Research Journal of Social Sciences, 8(2), $1-12$.

Mullis, I., Martin, M., Fierros, E. Goldberg, A., \& Stemler, S. (2000). Gender differences in achievement: IEA's Third International Mathematics and Science Study (TIMSS). Retrieved from http://timssandpirls.bc.edu/timss1995i/TIMSSPDF/t95_gender_all.pdf

OECD. (2011). Women economics empowerment. Issue Paper prepared by the DAC network on gender equality.

Rashidi, N., \& Naderi, S. (2012). The effect of gender on the patterns of classroom interaction. Retrieved from http://www.sapub.org/global/showpaperpdf.aspx?doi=10.5923/j.edu/20120203.02

Rayaprol, A. (2010). Gender equality in the classroom. Teacher Plus. Retrieved from http://www.teacherplus.org/things-to-think-about/gender-equality-in-the-classroom

Rowe, M. (1986). Wait time: slowing down may be a way of speeding up. Retrieved from http://www.sagepu.com/eis2study/articles/Budd\%20Rowe.pdf

Scantlebury, K. (2009). Gender bias in teaching. Retrieved from http://www.education.com/reference/article/gender-bias-in-teaching

Social Watch Report. (2007). Retrieved from http://www.socialwatch.org/node/9292

UNESCO Institute for Statistics .(UIS).(2007). Retrieved from http://www.uis.unesco.org/Pages/default.aspx

UNESCO Institute for Statistics. (UIS). (2010). Retrieved from http://www.uis.unesco.org/Pages/default.aspx

UNESCO, EFA Global Monitoring Report. (2008). Retrieved from http://www.unesco.org/new/en/education/themes/leading-the-international-agenda/efareport/

UNESCO. (2007). GENIA toolkit for promoting gender equality in education. Retrieved from http://www.unescobkk.org/education/gender/resources/genia-toolkit/

UNESCO. (2012). Retrieved from http://www.unesco.org/new/en/education/themes/leading-the-international-agenda/efareport/reports/201 2-skills/

UNESCO. (2014). Position paper on education post- 2015. Retrieved from http://en.unesco.org/post2015/

United Nations Millennium Goal 3. (2010). Promote gender equity and empower women. Retrieved from http://www.un.org/millenniumgoals/gender.shtml

Whiteley, P. (1996). The 'gender fairness' of integrated science textbooks used in Jamaican high schools. International Journal of Science Education, 18(8), 969-976. http://dx.doi.org/10.1080/0950069960180808

Yoshida, K. (2012). Gender perception in Southeast Asian countries: findings from JICA-RI values surveys. Retrieved from http://siteresources.worldbank.org/INTWDR2012/Resources/7778105-1299699968583/7786210-13226 71773271/yoshida-JICA-RI-Southeast-Asia-\%28Yoshida\%29.pdf 
Morales, M. P. E., Avilla, R. A., \& Espinosa, A. A.

Zadker, D., \& Zittleman, K. R. (2009). Still failing at fairness: How gender bias cheats girls and boys in school and what we can do about it. New York: The Gale Group, Inc. 